\title{
A UTILIZAÇÃO DO GEOPROCESSAMENTO NO LICENCIAMENTO AMBIENTAL DA ATIVIDADE MINERÁRIA NA BACIA HIDROGRÁFICA DO RIO SOROCABA
}

\section{THE USE OF GEOPROCESSING IN ENVIRONMENTAL LICENSING OF MINING ACTIVITY IN THE SOROCABA RIVER WATERSHED}

\section{Sonia Aparecida Abissi Nogueira ${ }^{1}$, Antonio Carlos Moretti Guedes $^{2}$, Hélio Shimada ${ }^{3}$, Márcia Maria Nogueira Pressinotti ${ }^{4}$, Pilar Martin Pi Lopez ${ }^{5}$}

${ }^{1}$ Pesquisadora Científica V, Instituto Geológico, Secretaria do Meio Ambiente do

Estado de São Paulo, e-mail: snogueira@igeologico.sp.gov.br

${ }^{2}$ Pesquisador Científico III, Instituto Geológico, Secretaria do Meio Ambiente do

Estado de São Paulo, e-mail:acguedes@igeologico.sp.gov.br

${ }^{3}$ Pesquisador Científico V, Instituto Geológico, Secretaria do Meio Ambiente do

Estado de São Paulo, e-mail:hshimada@igeologico.sp.gov.br

${ }^{4}$ Pesquisadora Científica VI, Instituto Geológico, Secretaria do Meio Ambiente do

Estado de São Paulo, e-mail:mpressinotti@igeologico.sp.gov.br

${ }^{5}$ Agente Técnico Ambiental, Agência Ambiental de Itu, Companhia Ambiental de

São Paulo - CETESB, email: sma.pilarl@cetesbnet.sp.gov.br

\section{RESUMO}

A necessidade de um instrumento de apoio ao processo de licenciamento ambiental da atividade minerária praticada na Bacia Hidrográfica do Rio Sorocaba, São Paulo, levou o Instituto Geológico - IG a desenvolver, em parceria com a Companhia Ambiental do Estado - (CETESB) uma ferramenta computacional apta a executar entrada, edição, consultas e visualização de dados relativos a esta atividade econômica. Tal ferramenta teve como objetivo proporcionar ao órgão licenciador uma análise regional que favoreça a identificação e avaliação de áreas críticas e dos potenciais conflitos associados, segundo critérios de adensamento, degradação ambiental, comprometimento dos recursos hídricos, proximidade com áreas urbanas e unidades de conservação. Este trabalho contextualiza a atividade na região e descreve a estrutura e principais funcionalidades do Sistema de Informações Georreferenciadas da Atividade Minerária na Bacia do Rio Sorocaba - SOROMIN. O desenvolvimento deste Sistema, concebido em um ambiente clienteservidor, compreendeu, essencialmente, a sua modelagem e a estruturação de um banco de dados, desenvolvidos a partir do levantamento das informações junto às Agências Ambientais da CETESB de Itu, Botucatu e Sorocaba, e envolveu a preparação e edição de diversos mapas temáticos. O sistema construído e em fase de implantação propicia o acesso e interação do usuário com um banco 
de dados georreferenciados sobre os empreendimentos e atividades de licenciamento, fiscalização e controle da mineração na área de abrangência da BHRS, o qual poderá ser estendido a outras agências ambientais do Estado.

Palavras chave: Sistema de informações georreferenciadas. Mineração. Licenciamento ambiental. Bacia hidrográfica do rio Sorocaba.

\begin{abstract}
The need for an instrument to support the environmental licensing of the mining activity held in the Sorocaba river watershed State of São Paulo, led the Geological Institute to develop, in partnership with the Environmental Company of State of São Paulo - CETESB, a computational tool able to perform the input, edition, queries and visualization of the mining companies data. The aim of this tool is to provide a regional analysis to the licensing agency favoring the identification and evaluation of critical areas and related potential conflicts, according to criteria of densification, environmental degradation, commitment of water resources, proximity to urban areas and conservation units. This paper expresses the activity in the region and describes the structures and main features of the Geographic Information System. The development of GIS, designed in a client-server environment, mainly comprised its modeling and database organization, developed from information assessment in the CETESB's environmental agencies of Itu, Botucatu and Sorocaba and involved the preparation and edition of several thematic maps. The developed and now being implemented system allows the user to access and interact with a georeferenced database of mining enterprises and licensing activities, mining supervision and control in the area of the watershed that may be extended to other environmental agencies of the State of São Paulo.
\end{abstract}

Keywords: GIS. Mining. Environmental license. Sorocaba river watershed.

\title{
1. INTRODUÇÃO
}

No contexto do desenvolvimento urbano e industrial, o processo de concentração demográfica expandiu a intensidade de consumo de substâncias minerais, que servem de base para o estilo de vida da sociedade moderna. A mineração se insere, neste cenário, como uma atividade industrial importante e necessária, inerentemente modificadora do meio ambiente e frequentemente associada às questões sociais, tais como conflitos pelo uso do solo e geração de áreas degradadas.

$\mathrm{Na}$ Bacia Hidrográfica do Rio Sorocaba (BHRS) a exemplo do que se verifica no restante do Estado do São Paulo a atividade minerária se caracteriza, principalmente, pela extração de bens minerais não metálicos para o uso imediato na indústria da construção civil. Os dados oficiais dos empreendimentos de mineração encontram-se dispersos, raramente com referência espacial associada, o que dificulta a sua consulta por parte dos órgãos responsáveis pelo licenciamento ambiental e fiscalização desta atividade econômica. Tal situação impede uma análise regional que favoreça a identificação e avaliação de áreas críticas e dos potenciais conflitos associados, segundo critérios de adensamento, degradação ambiental, comprometimento dos recursos hídricos, proximidade com áreas urbanas e unidades de conservação.

A partir deste quadro concretizou-se a necessidade do uso de novas tecnologias, como a modelagem de um sistema de informações, que permitisse estruturar um banco de dados georreferenciados, onde a mineração estivesse especializada e admitisse seu acompanhamento durante as etapas do processo de licenciamento ambiental, a exemplo do que realizaram BITAR et al. (2000), BESER DE DEUS et al. (2003) e FERREIRA e FERNANDES DA SILVA (2008).

O presente trabalho apresenta o Sistema de Informações Georreferenciadas da Atividade Minerária na Bacia do Rio Sorocaba, denominado SOROMIN, construído com a finalidade de ser 
utilizado como uma ferramenta mais ágil de análise, na rotina dos procedimentos do licenciamento ambiental da atividade minerária na BHRS, pelas Agências Ambientais de Botucatu, Itu e Sorocaba da CETESB.

\section{MATERIAIS E MÉTODOS}

O desenvolvimento do Sistema compreendeu, de início, a definição de propósitos e análise das demandas, por meio de levantamentos de junto às Agências Ambientais usuárias do recurso, seguida de modelagem do SIG e estruturação do banco de dados, preparação de bases cartográficas e temáticas, implementação do ambiente de hardware e software, alimentação e operação. Os dados que abastecem o Sistema são obtidos de forma automatizada (dados do licenciamento mineral junto ao Departamento Nacional da Produção Mineral - DNPM), ou manualmente, mediante análise de processos em tramitação no órgão ambiental.

\section{Localização}

A Bacia do Rio Sorocaba, localizada a oeste da cidade de São Paulo, faz parte da Unidade de Gerenciamento de Recursos Hídricos dos Rios Sorocaba e Médio Tietê - UGRHI 10. É constituída pelas sub-bacias do Baixo, Médio e Alto Sorocaba, com uma área de $5.269 \mathrm{~km}^{2}$, que compreende total ou parcialmente 29 municípios (Figura 1).

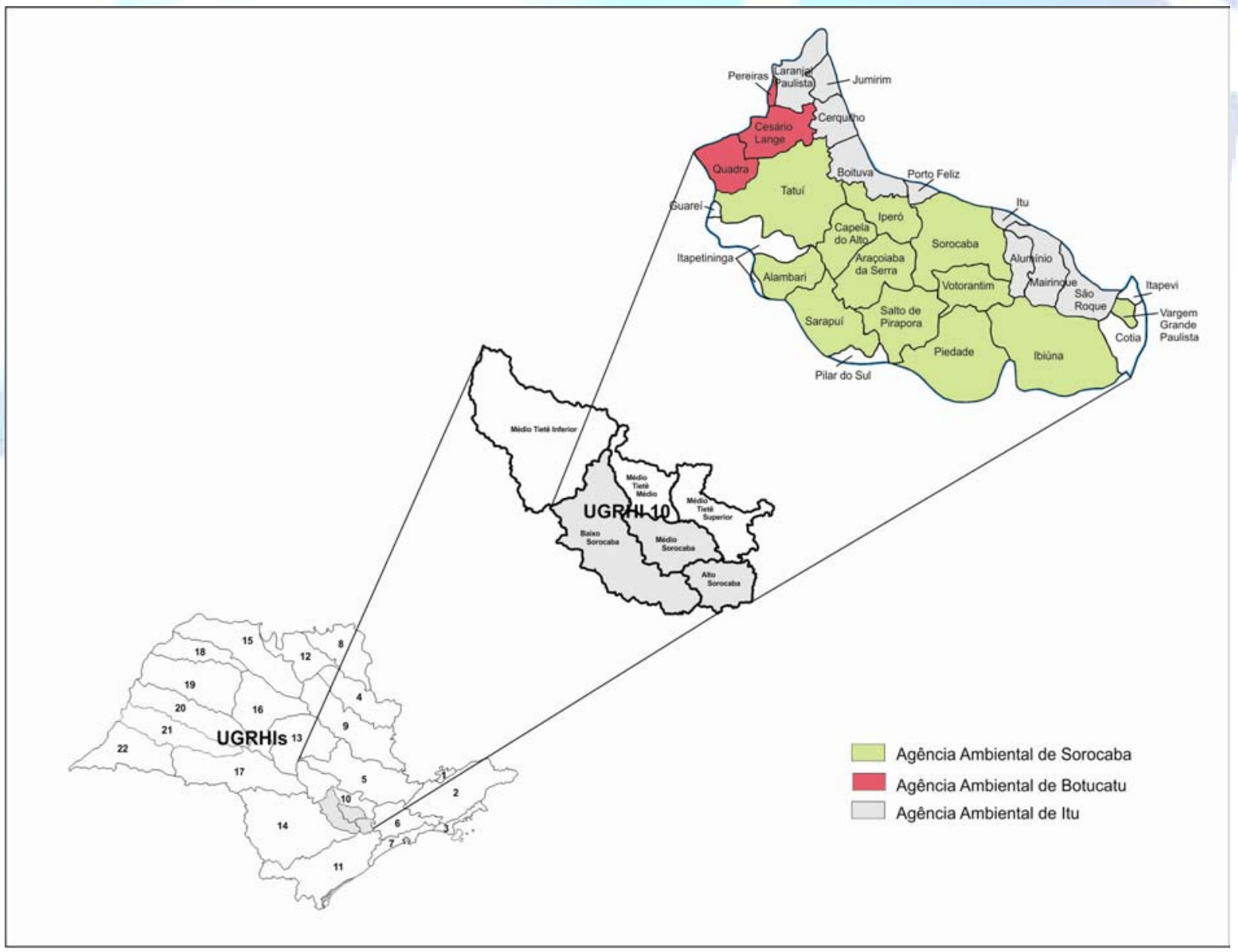

Figura 1. Bacia Hidrográfica do Rio Sorocaba - BHRS em relação à UGRHI 10, no Estado de São Paulo, e a divisão de sua administração pelas Agências Ambientais da CETESB de Sorocaba, Itu e Botucatu.

Fonte: Os autores 


\section{Contexto geológico, a potencialidade mineral e a atividade de mineração.}

A BHRS expõe em seu território terrenos sedimentares da Bacia do Paraná, rochas cristalinas do Embasamento e coberturas sedimentares recentes e atuais (TEIXEIRA, 2009). De acordo com os levantamentos de campo realizados para o desenvolvimento do trabalho, a potencialidade mineral associa-se, principalmente, aos folhelhos argilosos da Bacia Estratigráfica do Paraná, aos maciços granitóides dos complexos cristalinos e às lentes de rochas carbonáticas do Embasamento Precambriano e aos aluviões recentes a atuais relativas às Coberturas Cenozóicas, constituídos, principalmente, pelas areias dos leitos dos rios e das planícies de inundação.

A atividade minerária aí existente se caracteriza pela extração de bens minerais não metálicos, principalmente areias e britas para construção civil, argilas para o setor cerâmico, rochas carbonáticas para a indústria cimenteira, de cal e de fertilizantes e água mineral para consumo humano. Nos últimos cinco anos, a UGHRI 10, onde se insere a BHRS, vem se mantendo entre as primeiras posições do Estado de São Paulo em produção mineral (DNPM, 2010), respondendo em 2010 pela primeira colocação no valor de produção de rochas carbonáticas (municípios de Salto de Pirapora, Votorantim e Pereiras), segundo lugar nas produções de argilas para cerâmica vermelha (Laranjal Paulista, Tatuí, Itu e Cesário Lange) e de areia industrial (Bofete) e pela quarta posição na produção de britas (Sorocaba). A mineração, assim como outras atividades econômicas desenvolvidas na BHRS, tem seu licenciamento ambiental realizado pelas Agências Ambientais de Sorocaba, Itu e Botucatu, da CETESB.

\section{Levantamento dos empreendimentos de mineração}

O levantamento dos dados foi realizado mediante análise dos processos de licenciamento mineral em tramitação na CETESB, e computou no segundo semestre de 2009, 249 empreendimentos minerários licenciados, entre ativos, paralisados e encerrados. Na Agência Ambiental de Sorocaba foram registrados 142 empreendimentos, enquanto que nas Agências Ambientais de Itu e Botucatu registraram-se, respectivamente, 78 e 29 empreendimentos. A atividade extrativa de sedimentos argilosos, para o uso na indústria cerâmica, predomina sobre os demais bens minerais em todas as agências. A exploração de areias para uso imediato na construção civil e de rochas calcárias para indústria cimenteira e de cal vêm na sequência, com destaque para a Agência de Sorocaba.

\section{Arquitetura do Sistema de Informações}

O processo de construção do Sistema de Informações Georreferenciadas da Mineração na Bacia do Rio Sorocaba - SOROMIN contemplou de início uma série de reuniões técnicas e consultas às Agências Ambientais da CETESB, de forma que os propósitos e a demanda de uso do sistema fossem claramente definidos, além de avaliar preliminarmente o universo de dados e conteúdo a ser sistematizado. Foi concebido um produto computacional em formato clienteservidor, de maneira a permitir entrada de dados, acesso, análises e consultas remotas. Em sua arquitetura, mostrada na Figura 2, o SOROMIN integra um servidor de dados (espaciais e alfanuméricos) instalado na Agência Ambiental de Sorocaba, às máquinas clientes localizadas no Instituto Geológico e nas Agências de Sorocaba, Itu e Botucatu, com a utilização do ambiente da rede da CETESB. 


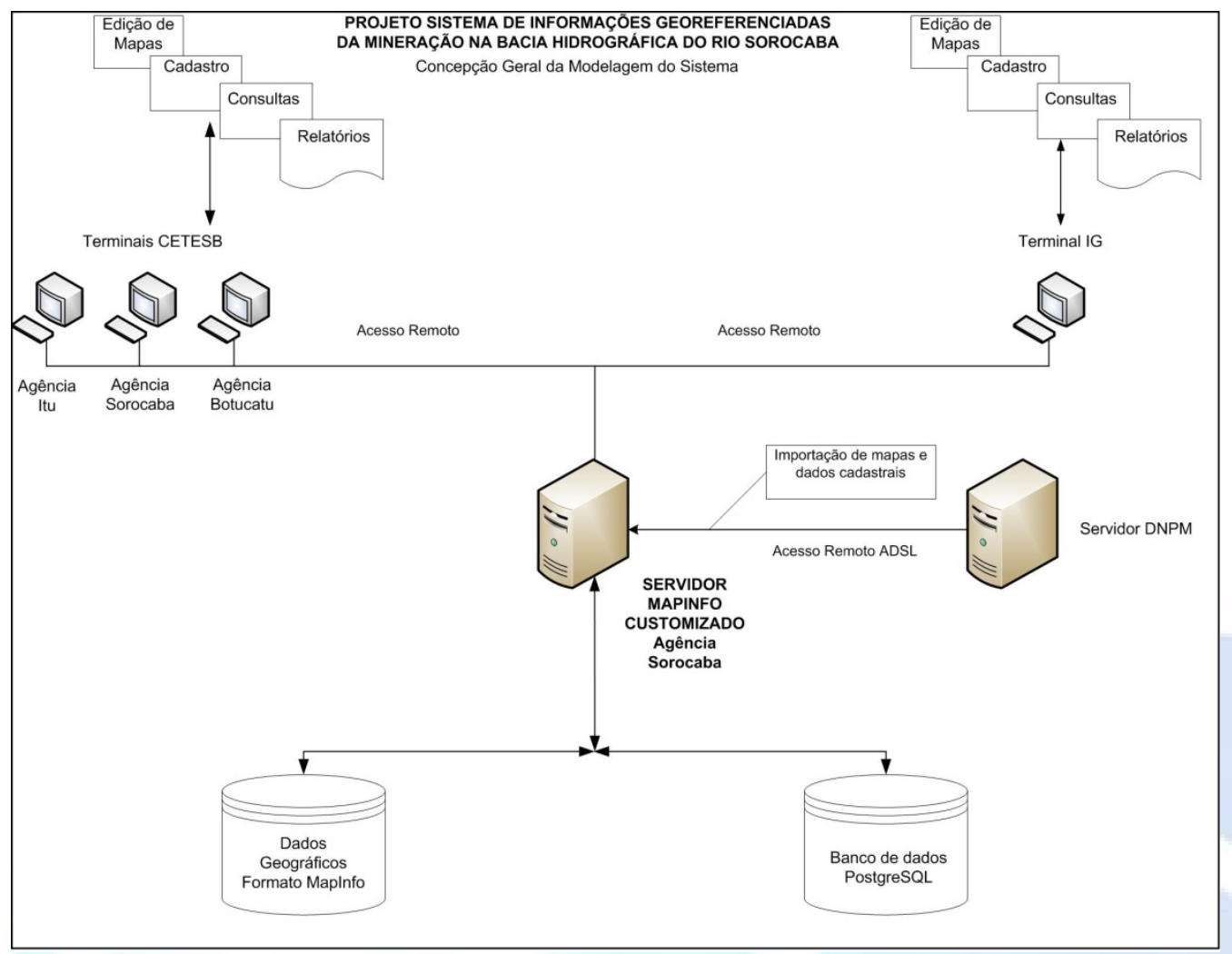

Figura 2. Esquema da concepção do Sistema de Informações Georreferenciadas da Mineração na Bacia Hidrográfica do Rio Sorocaba - SOROMIN, desenvolvido pelos autores.

\section{Concepção e modelagem do banco de dados}

Estabelecido em uma arquitetura que utiliza o software MapInfo Professional como módulo gráfico, e o sistema gerenciador de banco de dados de código aberto PostgreSQL, o sistema foi customizado e programado com as ferramentas de programação MapBasic, (integrada ao MapInfo Professional) e "C\#", uma linguagem orientada a objetos desenvolvida pela Microsoft, com o intuito de se obter um produto computacional de fácil utilização pelos técnicos envolvidos com o licenciamento ambiental.

O sistema foi instalado em um servidor baseado em um processador Intel i7, 2,86 GHz, dotado do sistema operacional Windows Server 2007. O acesso é feito por meio de conexões remotas ao servidor, em redes Windows, a usuários cadastrados dentro do próprio sistema, sendo executado como uma aplicação, por meio de uma customização do programa MapInfo, instalado unicamente no servidor.

A modelagem do banco de dados foi realizada por meio do estudo de modelos passíveis de adoção para a representação dos elementos de informação essenciais aos objetivos propostos, buscando sempre a mais estreita interação com os seus usuários.

A base de dados do sistema é composta por um conjunto de informações que compreende mapas, metadados, dicionários de dados e cadastro de informações ambientais e minerárias. $\mathrm{Na}$ modelagem foram estruturadas as tabelas (de mapas e de informações alfanuméricas) e seus relacionamentos. Os dados que integram o sistema provêm de diferentes fontes, com distintos formatos (analógicos e digitais) e foram submetidos a tratamentos e edições rigorosas. As tabelas de mapas são constituídas pelas informações gráficas (cartográficas e temáticas) geométrica e topologicamente ajustadas e atributadas, de modo a facilitar as consultas e deslocamentos em campo. 


\section{RESULTADOS E DISCUSSÕES}

O Sistema de Informações SOROMIN foi concebido para, em um ambiente cliente-servidor, propiciar acesso e interação com um banco de dados georreferenciados sobre as atividades de licenciamento, fiscalização e controle da mineração, na área de abrangência da Bacia do Rio Sorocaba. É produto da atuação do Instituto Geológico nas áreas de Recursos Minerais e Geoinformação e apresenta várias distinções metodológicas em relação amodelos desenvolvidos pelo IG em outras regiões do Estado, como na Bacia do Rio Mogi Guaçu (GUEDES e PRESSINOTTI, 2004) e Ubatuba (GUEDES e FERREIRA, 2008), notadamente quanto à arquitetura adotada, possibilidade de atualização de informações online e hierarquização de níveis de acesso.

Este Sistema possui um administrador geral, que pode criar e gerenciar usuários com três diferentes níveis de acesso: a) administrador, a quem são permitidas e designadas tarefas específicas como criação de novos usuários, execução de rotinas internas, b) operador, cuja função se pauta na entrada de dados de empreendimentos minerários, consultas e geração de relatórios e c) leitor, com possibilidades restritas de consulta.

As funcionalidades presentes no Sistema SOROMIN são igualmente disponibilizadas de acordo com o nível de acesso do usuário conectado. Como exemplo, a atualização online dos dados do Departamento Nacional de Produção Mineral - DNPM, apenas pode ser executada por usuário administrador, assim como a criação e exclusão de novos usuários e inserção de arquivos de dicionários de dados.

O SOROMIN apresenta um ambiente georreferenciado onde diferentes mapas, designados temas, podem ser carregados pela aplicação, cada um deles representando a organização de diversos planos de informação (layers), aos quais se sobrepõe, sempre, um plano específico representando os Empreendimentos Minerários, objeto de licenciamento.

\section{Preparação e edição dos mapas temáticos}

As atividades desta etapa envolveram o levantamento e a adequação de material cartográfico necessário ao suporte da edição de mapas temáticos, fundamentais para a análise dos processos de licenciamento ambiental. Produtos vetoriais e matriciais foram avaliados e uma base cartográfica baseada nas folhas IBGE e IGG 1:50.000, além de imagens de satélite TM LANDSAT-5 e um Modelo Digital de Terreno, foram consolidadas e portadas para o ambiente do sistema.

$\mathrm{Na}$ fase seguinte, baseado na modelagem prévia, foram organizadas sobre o arcabouço cartográfico as informações temáticas compatíveis com as necessidades de visualização, consulta e análise espaciais voltadas aos trabalhos cotidianos dos técnicos do órgão ambiental. Baseados no ambiente SIG do software MapInfo Professional, os diferentes temas são oferecidos como fundo para todas as consultas, visualizações e entradas de dados, sendo que a escolha de cada um, em particular, depende do objetivo da operação. Por sua importância, os metadados completos de todas as informações que compõem o sistema podem ser consultados dentro da aplicação. A seguir, apresenta-se o elenco dos temas disponíveis no Sistema, com breve descrição do plano de informação principal.

- Base Cartográfica, reunindo informações de altimetria, hidrografia, malha viária e ferroviária, malha municipal e outras;

- Mapa Geológico, compilado a partir de diversas fontes e datas pelo projeto Cartografia Geológica Digital da Bacia Hidrográfica do Rio Sorocaba (TEIXEIRA, 2009);

- Mapa de Recursos Hídricos, com informações básicas do Departamento de Águas e Energia Elétrica - DAEE e Companhia Ambiental de São Paulo (IPT, 2006);

- Mapa de Uso do Solo, adaptado do Mapeamento Temático do Uso e Ocupação do Solo do Estado de São Paulo (SMA - Coordenadoria de Planejamento Ambiental, 2007); 
- Mapa de Vegetação Natural e Áreas Reflorestadas, com dados provenientes do Inventário Florestal da Vegetação Natural do Estado de São Paulo (SMA - Instituto Florestal, 2005);

- Mapa de Unidades de Conservação, elaborado a partir de dados do Atlas de Unidades de Conservação do Estado de São Paulo (SMA, 2000);

\section{CETESB;}

- Mapa das Agências Ambientais, mostrando a área de atuação de cada unidade da

- Mapa de Títulos Minerários - com dados do Departamento Nacional da Produção Mineral - DNPM, a partir de informações fornecidas pelo Sistema de Informações Geográficas da Mineração/SIGMINE (disponível em http://sigmine.dnpm.gov.br/), atualizadas semanalmente por meio de rotina de importação e conversão interna do Sistema SOROMIN;

- Mapa de Relevo, baseado no Modelo Digital de Elevação Global gerado pelo processamento e correlação estereoscópica de imagens óticas individuais obtidas pelo Radiômetro de Reflexão e Emissão Termal (Aster), sensor japonês a bordo do satélite Terra (Referência: http://asterweb.jpl.nasa.gov/gdem.asp);

- Mosaico de Imagem de satélite TM-LANDSAT-5, composição RGB a partir de imagens obtidas gratuitamente pela internet junto ao Banco de Imagens do DGI/INPE em http://www.dgi.inpe.br/CDSR/.

A Figura 3, a seguir, exemplifica dois tipos de temas desenvolvidos. 


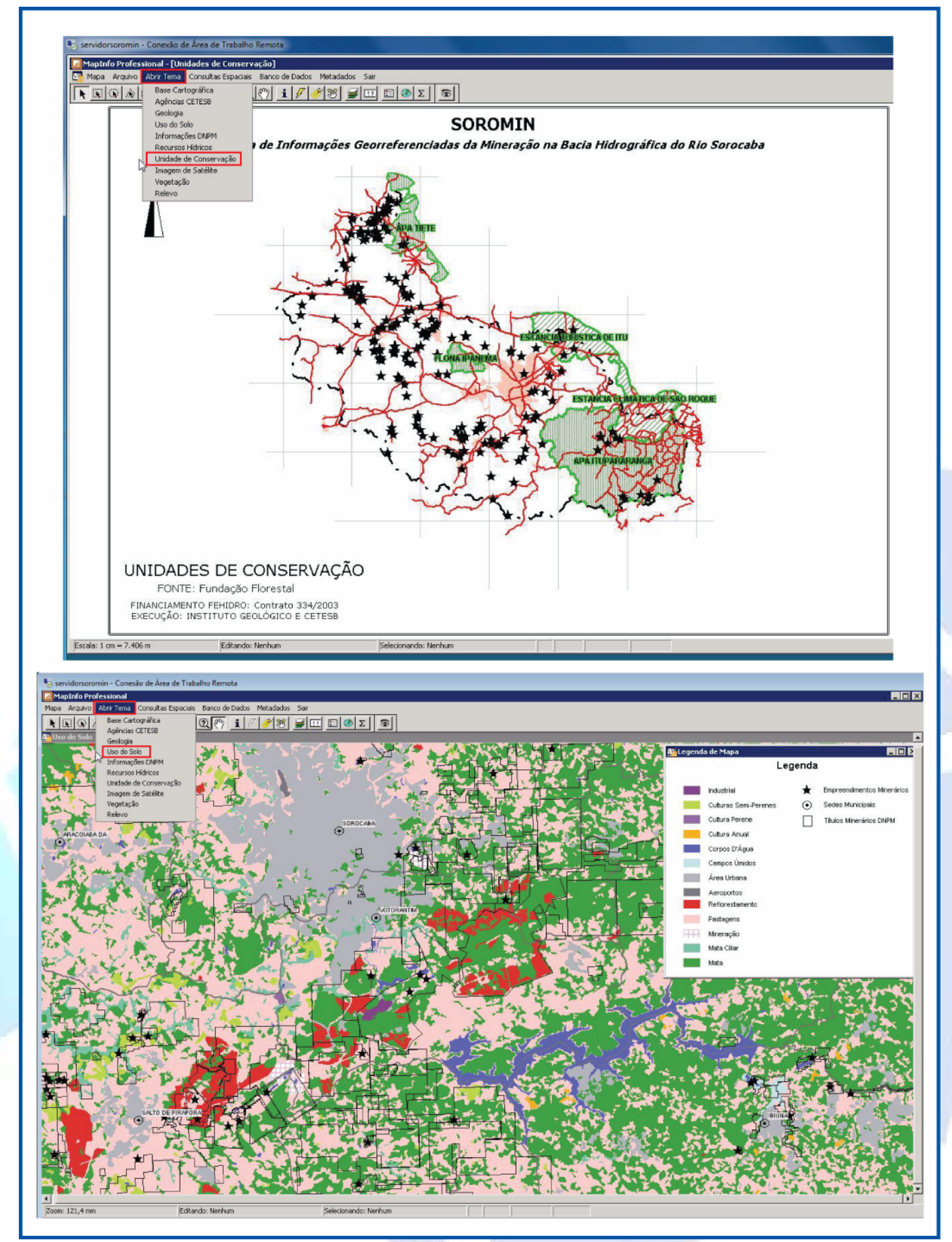

Figura 3. Apresentação dos temas disponíveis para visualização e consulta. A alternância entre eles é feita pelo menu superior do sistema. Em destaque, os temas Unidades de Conservação e Uso do Solo, onde os pontos se referem aos empreendimentos minerários do banco de dados.

\section{Criação de ambiente customizado}

Associado ao ambiente georreferenciado expresso nos temas citados, o Sistema integra o conteúdo do Banco de Dados de Empreendimentos Minerários com funcionalidades customizadas ao ambiente gráfico, de entrada e consulta de dados, consultas espaciais a determinados componentes dos temas, exportação de relatórios em formato de planilha eletrônica e PDF, geração de layout gráfico para impressão posterior, dentre outras. Na Figura 4 são mostradas diferentes funcionalidades implementadas no SOROMIN. 


\section{Banco de Dados: entrada de informações}

O conjunto de dados relativos aos empreendimentos minerários cadastrados nas três Agências Ambientais está armazenado em um banco de dados externo, no padrão PostgreSQL, que se integra ao ambiente MapInfo como um plano de informação de elementos pontuais. Buscou-se a melhor customização para oferecer uma interface específica e amigável, a partir do próprio ambiente da aplicação, com opções de consultas, entrada de novos dados e atualização de dados existentes. A visualização espacial dos empreendimentos minerários é facilitada pela possibilidade de alternância dos componentes espacial e alfanumérico.

A alimentação (entrada ou edição de dados) do sistema SOROMIN é executada por meio de um formulário invocado pelo menu suspenso, com separações de tópicos (abas) para preenchimento das informações dos empreendimentos de mineração. $\mathrm{O}$ banco de dados conta com os seguintes grupos de informações: a) Cadastro, localização e documentação; b) Reserva mineral e seu aproveitamento; c) Aspectos gerais e ambientais; d) Situação legal; e) Recursos hídricos; f) Histórico do empreendimento e registro fotográfico e g) Vegetação e intervenções. Na Figura 5 observam-se todos os tópicos do formulário de dados, com destaque para a aba de situação legal.

Este formulário foi baseado no Memorial de Caracterização do Empreendimento - MCE de Atividades Minerárias da CETESB, e sua modelagem apoiou-se na criação de diversos dicionários, com os campos de preenchimento agrupados em temas afins. Como resultado obteve-se grande facilidade e agilidade na entrada de dados, o que deverá ocasionar uma melhoria acentuada na rotina dos procedimentos operacionais do licenciamento ambiental. 


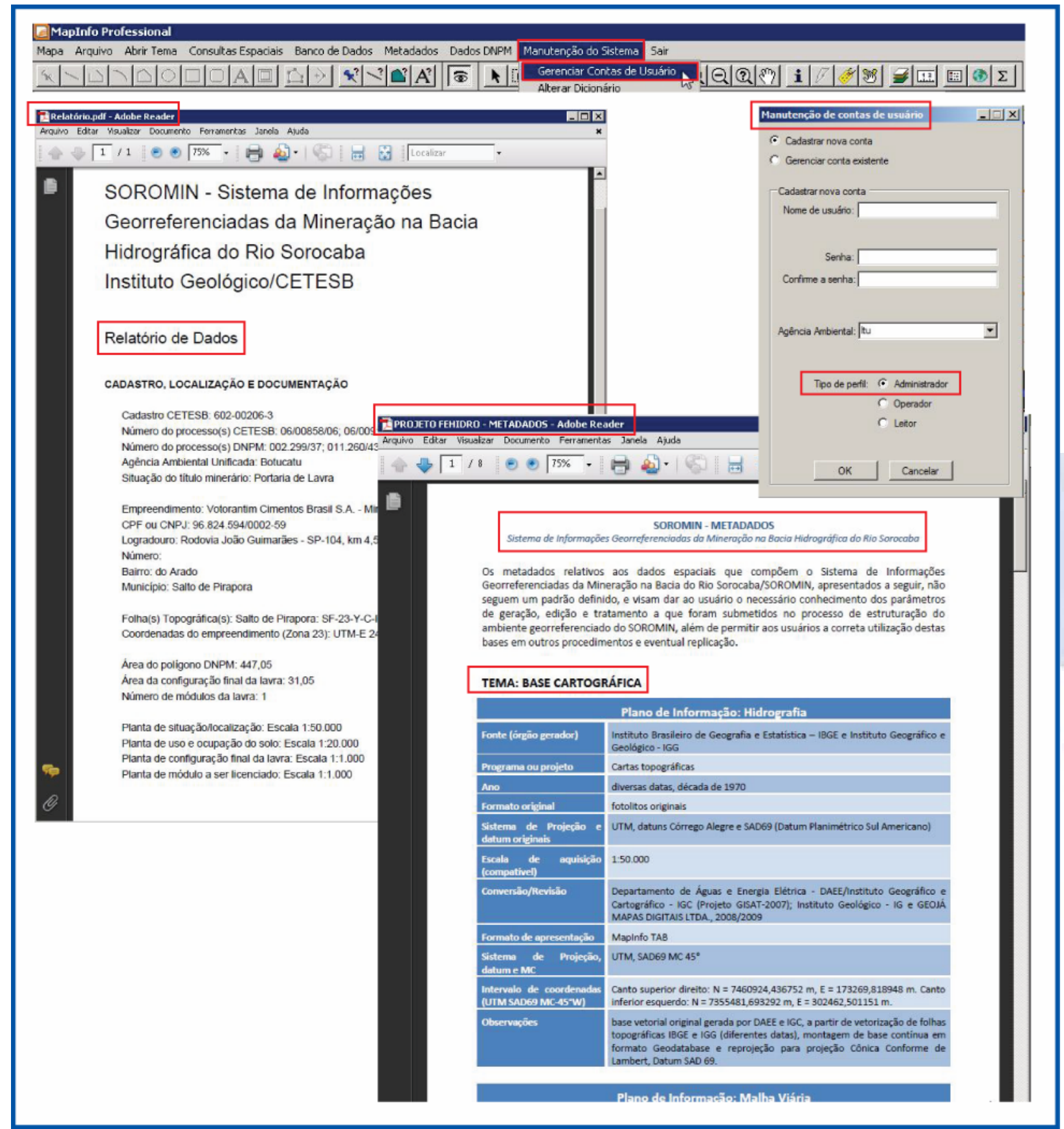

Figura 4. Exemplos de funcionalidades do SOROMIN: o usuário administrador possui nível pleno de acesso e gerenciamento do Sistema, sendo o único apto a cadastrar e gerenciar contas de usuários; diversas rotinas foram incorporadas ao Sistema, permitindo diferentes formas de saída de informações alfanuméricas, como os relatórios de dados e de metadados exibidos. 


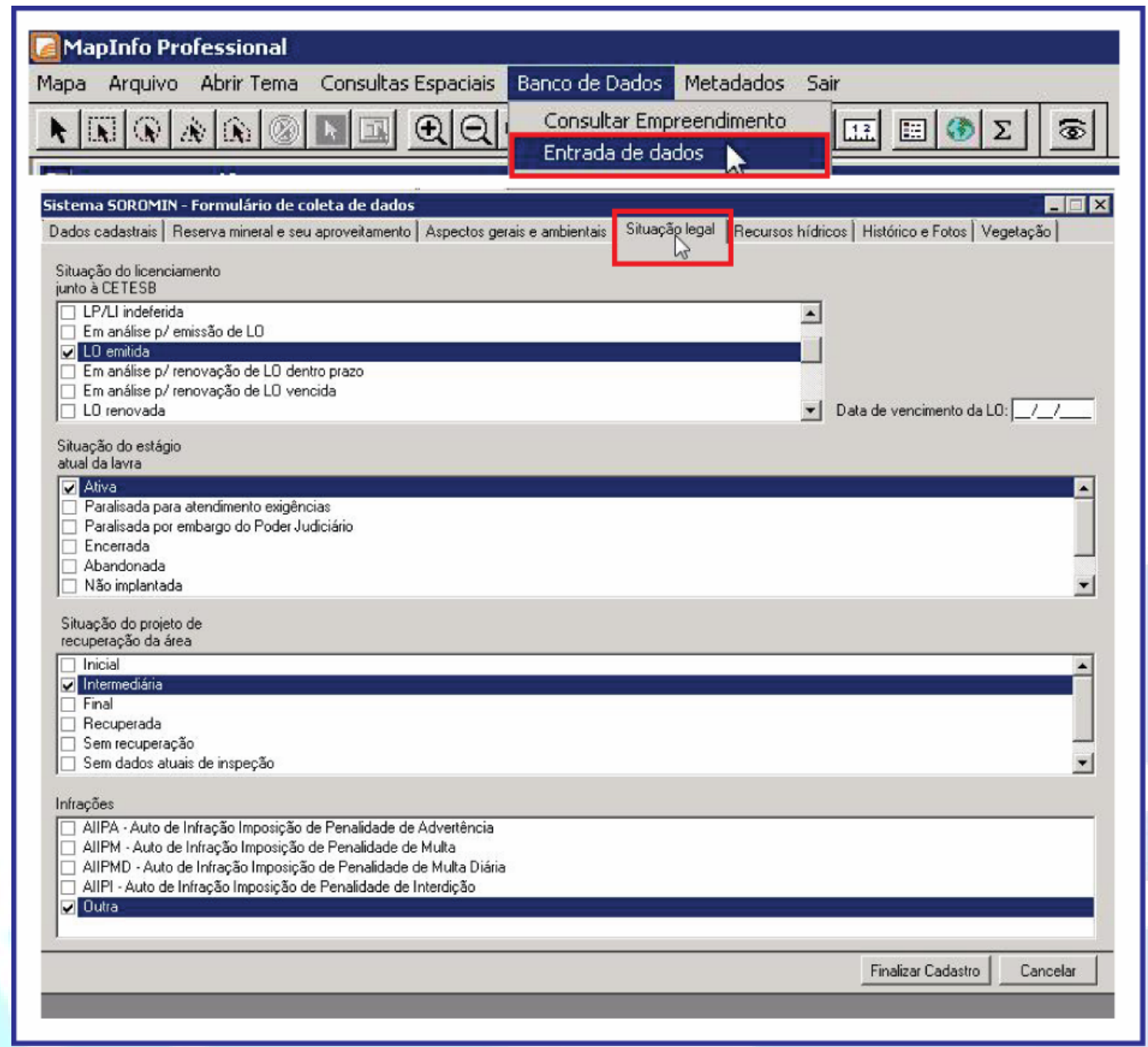

Figura 5. Exemplifica o ambiente e os grupos de informações que compõem o formulário de coleta do banco de dados do SOROMIN. Em destaque a aba de situação legal, observando alguns dos vários dicionários criados.

\section{Banco de Dados: consulta aos empreendimentos minerários}

Dentre as diversas funcionalidades do SOROMIN, destaca-se a capacidade da consulta aos empreendimentos minerários do banco de dados, realizada por meio de uma caixa de diálogo do menu suspenso, onde dois tipos de pesquisa são apresentadas: geral e específica. A Figura 6 mostra o resultado de uma consulta geral, cujo critério de ordenação escolhido foi o munícipio, revelando um total de 249 registros no banco de dados. Aparece com destaque, a seleção de um empreendimento, localizado sobre o tema Base Cartográfica. E a Figura 7 apresenta o resultado de uma consulta específica, cujo parâmetro selecionado foi o bem mineral explorado, dentre as diversas opções oferecidas. O resultado aponta 12 registros no banco de dados para esta situação de escolha, e o empreendimento selecionado é visualizado, também, sobre o tema Base Cartográfica. 


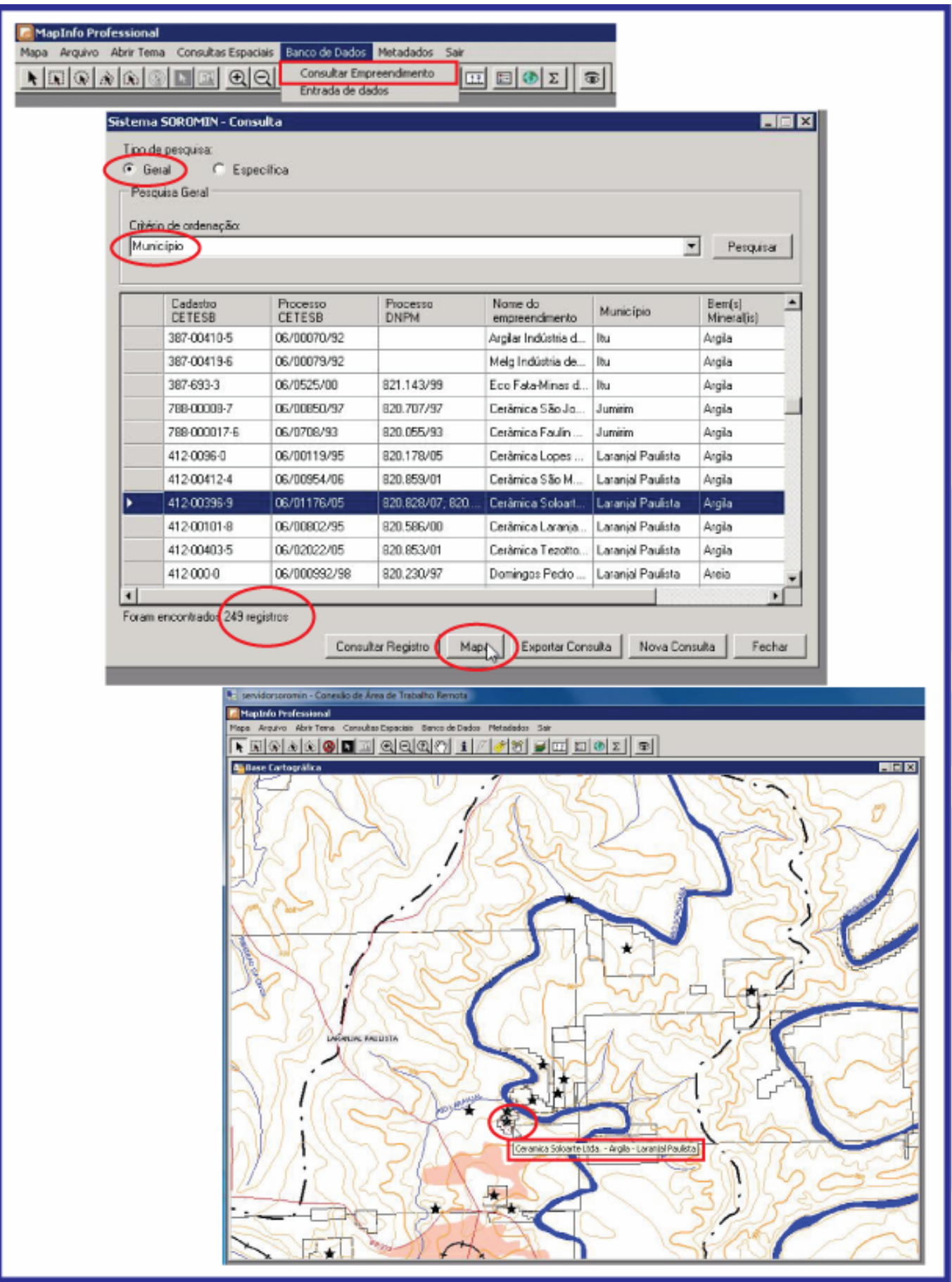

Figura 6. Exemplo de consulta ao banco de dados dos empreendimentos minerários, destacando-se a escolha de pesquisa do tipo geral, com critério de ordenamento por município. Na caixa de diálogo resultante observa-se a seleção do empreendimento consultado e sua localização no tema Base Cartográfica. 


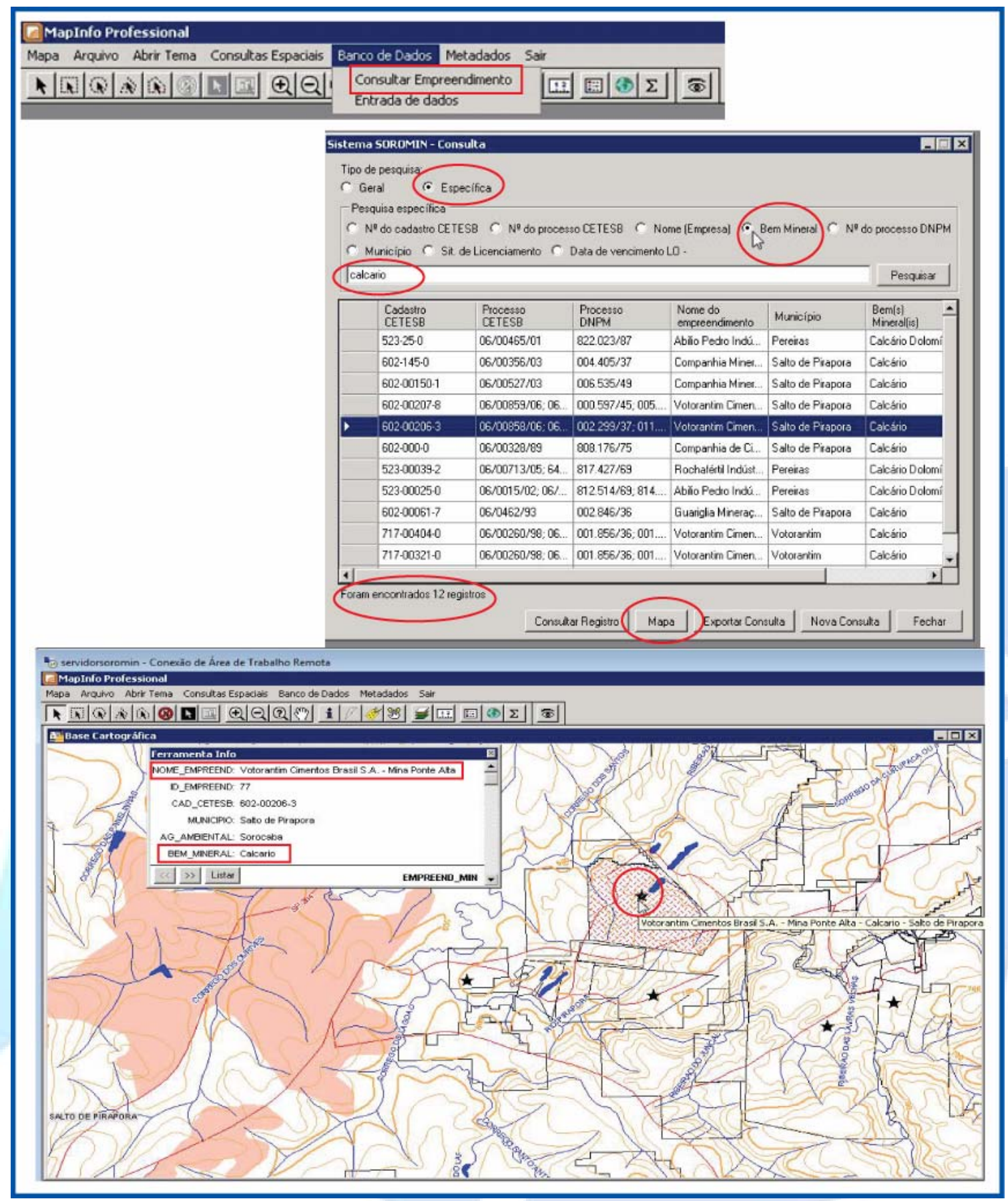

Figura 7. Exemplo de consulta ao banco de dados dos empreendimentos minerários, destacando-se a escolha de pesquisa do tipo específica, com opção de escolha por bem mineral. Na caixa de diálogo resultante é mostrada a seleção do empreendimento consultado e sua localização no tema Base Cartográfica. Observa-se, também, janela resultante do uso da ferramenta de informação (i) do menu suspenso, que foi aplicada ao objeto selecionado.

\section{Consulta espacial}

Outra funcionalidade do SOROMIN, de grande importância para o usuário do sistema, é a sua capacidade de executar consulta espacial, sob duas condições: a determinados componentes dos temas e a empreendimentos do banco de dados. 
$\mathrm{Na}$ primeira forma, os componentes que podem ser selecionados para consulta são: limites municipais, corpos d'água e malha viária. A Figura 8 exemplifica os passos de uma consulta espacial por temas, utilizando-se o componente, limites municipais.

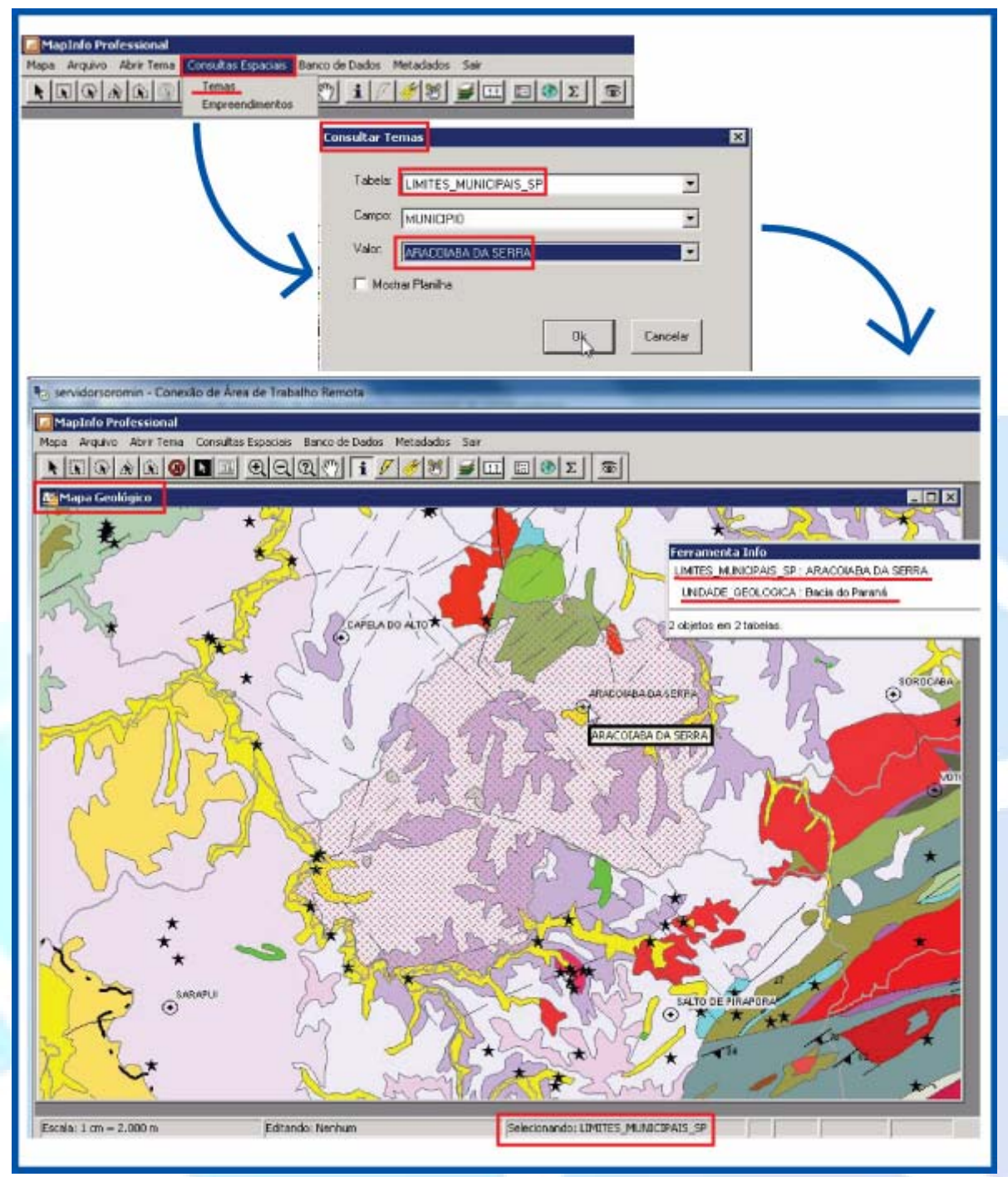

Figura 8. Exemplo de uma consulta espacial por tema, com destaque para uma consulta utilizando-se do componente limites municipais. Na caixa de diálogo resultante, observa-se a seleção do Município de Araçoiaba da Serra sobre o tema Geologia.

Na segunda condição possível de consulta espacial, o empreendimento minerário constitui o objeto principal da consulta, a partir de uma seleção que poderá considerar a escolha de qualquer um dos seguintes parâmetros: nome, município, agência ambiental ou corpo receptor. A Figura 9, a seguir, apresenta os passos de uma consulta espacial, utilizando-se o parâmetro nome do empreendimento. 


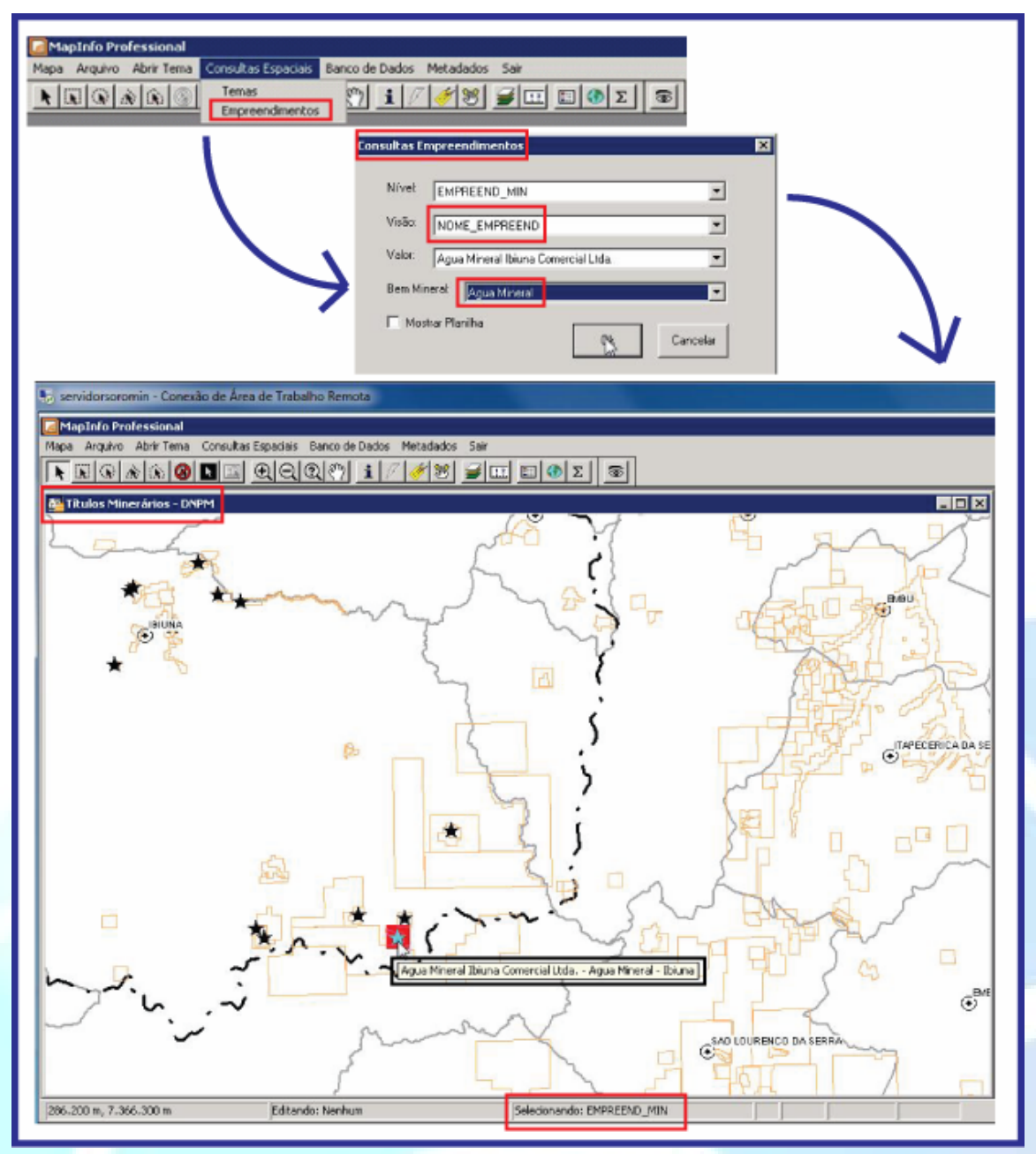

Figura 9. Exemplo de consulta espacial por empreendimento, com destaque para o parâmetro nome (Água Mineral Ibiúna Comercial Ltda.) e do bem mineral (Água Mineral). Na caixa de diálogo resultante, está localizado o empreendimento selecionado sobre o tema Títulos Minerários do DNPM.

\section{CONCLUSÕES}

A utilização do SOROMIN, como instrumento auxiliar do licenciamento, fiscalização e controle ambiental da CETESB, permitirá agilizar o monitoramento da atividade de mineração, pela sistematização dos dados e geração de instrumentos de visualização, consultas e análises espaciais, além de contribuir para o planejamento e gestão ambiental da atividade minerária. Por outro lado, pretende-se que este sistema venha configurar um piloto, pois seu modelo de concepção apresenta possibilidades de adaptação tanto na questão de inclusão de novos módulos (para contemplar outras atividades econômicas licenciadas na Bacia do Rio Sorocaba), como na replicação a outras agências ambientais do Estado.

\section{AGRADECIMENTOS}

Agradecemos ao Fundo Estadual de Recursos Hídricos - FEHIDRO, pelo auxílio financeiro (Contrato $\mathrm{N}^{\mathrm{o}} 334 / 2003$ ), que permitiu o desenvolvimento do aplicativo aqui apresentado, realizado pela parceria entre o IG e a CETESB. Agradecemos, também, à empresa Geojá Mapas Digitais 
Ltda., pelos serviços técnicos especializados em geoprocessamento prestados em diferentes fases de elaboração do SIG.

\section{REFERÊNCIAS}

BESER DE DEUS, L.A.; MENEZES, P.M.L.; PEITER, C.C.. Geoprocessamento aplicado à gestão de áreas de produção mineral. Anais... XXI Congresso Brasileiro de Cartografia, Belo Horizonte, MG, 2003.

BITAR, O.Y.; IYOMASA, W.S.; CABRAL JR, M. Geotecnologia: tendências e desafios. Revista São Paulo Perspectiva, jul/set, v.14, nº 3, 2000.

FERREIRA, C; FERNANDES DA SILVA, P.C. O uso de sistema de informação geográfica na priorização de áreas para aproveitamento mineral de saibro em áreas degradadas, Ubatuba, SP. Revista do Instituto Geológico, São Paulo, v.29, n. 1e 2, p. 19 - 31, 2008.

GUEDES, A. C. M.; PRESSINOTTI, M. M. N. Sistema de informações sobre a atividade minerária na bacia do rio Mogi Guaçu: uma ferramenta voltada ao planejamento e gestão. Anais... $5^{\circ}$ Simpósio Brasileiro de Cartografia Geotécnica e Geoambiental, São Carlos, SP, p. 32- 336, 2004.

GUEDES, A.C.M.; FERREIRA, C.J. Sistema Gerenciador de Informações Geoambientais. In: FERREIRA, CJ (Coord.). Diretrizes para a regeneração sócio-ambiental de áreas degradadadas por mineração de saibro (caixas de empréstimo), Ubatuba, SP. Relatório Técnico (inédito), FAPESP (processo FAPESP 03/07182-5). 2008.

DNPM - DEPARTAMENTO NACIONAL DA PRODUÇÃO MINERAL. Diretoria de Planejamento e Arrecadação/DIPAR. Arrecadação da Compensação Financeira por Exploração dos Recursos Minerais/CFEM no Brasil, 2010. Disponível em: http://www.dnpm.gov.br Acesso em: 13 jul. 2011.

DNPM - DEPARTAMENTO NACIONAL DE PRODUÇÃO MINERAL SIGMINE - Sistema de Informações Geográficas da Mineração. Disponível em http://sigmine.dnpm.gov.br/ Acesso em: 20 jun. 2011.

TEIXEIRA, A. L. (ORG.). Publicação em mídia eletrônica das cartas geológicas executadas pelo Instituto Geológico (SMA/SP) para subsidiar a ocupação e uso do meio físico na região de entre Sorocaba e Campinas. Instituto Geológico, 2009. Disponível em http://www.igeologico.sp.gov.br/ Acesso em: 13 jul. 2011.

INSTITUTO DE PESQUISAS TECNOLÓGICAS, IPT. Plano de Bacia da Unidade de Gerenciamento de Recursos Hídricos do Sorocaba e Médio Tietê (UGRHI 10). Relatório Técnico Final No 91.265-205, 153p. 2006.

SECRETARIA DO MEIO AMBIENTE, SÃO PAULO. Atlas das Unidades de Conservação Ambiental do Estado de São Paulo. 2000. 
SECRETARIA DO MEIO AMBIENTE, SÃO PAULO. Coordenadoria de Planejamento Ambiental. Mapeamento Temático do Uso e Ocupação do Solo do Estado de São Paulo. (Relatório inédito) 2007.

SECRETARIA DO MEIO AMBIENTE, SÃO PAULO. Instituto Florestal. Inventário Florestal da Vegetação Natural do Estado de São Paulo. 2005. Disponível em:

http://www.iflorestal.sp.gov.br/sifesp/publicacoes.html. Acesso em: 20 jun. 2011. 